\title{
Aetiology of duodenal ulcer: an investigation into the buffering action and effect on pepsin of bran and unrefined carbohydrate foods
}

\author{
Frank I. TOVEY \\ O.B.E., CH.M., F.R.C.S. \\ Basingstoke District Hospital (late Holdsworth Memorial Hospital, Mysore City, S. India)
}

\begin{abstract}
Summary
It is unlikely that any possible protective action of wheat or rice bran or certain unrefined grains against peptic ulceration is due to any acid or pepsin lowering effect. Although these substances contain significant amounts of buffer, they also act as antral stimulants resulting in increased acid output. They also have no inhibitory effect on pepsin activity.
\end{abstract}

IT has been suggested that the refinement of staple carbohydrate foods may be a major aetiological factor in accounting for the appearance and the rising incidence of duodenal ulcer, both in Western countries and in developing countries, during the present century (Cleave, 1962, 1974). Cleave postulated that this may be due to loss of buffer in the staple carbohydrates as a result of the removal of bran by milling or the loss of protein by other methods of processing as in the preparation of manioc (cassava) and the manufacture of white sugar. He lays particular emphasis on the value of protein as a buffer. It is also suggested that the buffering effect of protein may be enhanced as it is digested and broken down into polypeptides, peptones and amino acids (Levy and Siler, 1942).

Cleave's hypothesis fits in with the situation in rural India where duodenal ulcer is common in the south and in parts of Kashmir, Assam and Bengal, areas in which milled rice is the staple food, and is rare in those areas of the north where the staple diet is unrefined wheat. Duodenal ulcer is also common in those areas of the south where cassava replaces rice. In Mysore the author found a lower incidence amongst those whose staple diet was ragi (Eleusine coracana), an unrefined millet. The incidence, however, was high in areas of the Deccan where another unrefined grain, jowar or cholam (Sorghum vulgare), was the staple food (Tovey, 1972c).

Information being obtained by Mr D. P. Burkitt and the author from all parts of Africa shows that there is a high incidence of duodenal ulcer in rural areas in a belt along the West Coast and in Ethiopia, southern Uganda, and particularly in Rwanda and Burundi and the hilly areas of northern Tanzania.
There are large areas of low incidence in northern Uganda, most of Zaire, Kenya, Tanganyika, Zambia, Malawi, Lesotho, Natal and the Transvaal. As yet no distinctive pattern of dietary differences between high and low incidence areas has emerged, except that duodenal ulcer is rare in all the rural areas where unrefined maize is the staple food.

Cleave $(1962,1974)$ also gathered information from prisoner of war camps and from the German army before Stalingrad which suggested that the change to unrefined carbohydrate diets may benefit patients with duodenal ulcer and this was supported by the use of rice bran by the author in the treatment of patients in India (Tovey, 1972a, b).

With the above situations in mind the staple carbohydrate foods from some of the different areas mentioned were investigated, both in vitro and in vivo, for their buffering action and also for their effect on pepsin activity. Their effect on gastric secretion was also compared with the effect of milk and of antacids.

TABLE 1. Protein, calcium, phosphorus and magnesium content

\begin{tabular}{|c|c|c|c|c|}
\hline Per $100 \mathrm{~g}$ & $\begin{array}{l}\text { Protein } \\
\text { (g) }\end{array}$ & $\begin{array}{l}\text { Calcium } \\
(\mathrm{mg})\end{array}$ & $\begin{array}{l}\text { Phosphorus } \\
\text { (mg) }\end{array}$ & $\begin{array}{l}\text { Magnesium } \\
\text { (mg) }\end{array}$ \\
\hline Rice bran & $10 \cdot 0$ & $10 \cdot 0$ & 510 & 366 \\
\hline Wheat bran & $14 \cdot 7$ & $8 \cdot 7$ & 856 & 321 \\
\hline Maize & $11 \cdot 1$ & $10 \cdot 0$ & 330 & 40 \\
\hline Ragi & 6.0 & 282.0 & 231 & 191 \\
\hline $\begin{array}{l}\text { Wholemeal } \\
\text { wheat }\end{array}$ & $12 \cdot 1$ & $40 \cdot 0$ & 320 & 106 \\
\hline $\begin{array}{l}\text { (Jowar) } \\
\text { Polished }\end{array}$ & $10 \cdot 4$ & 30.0 & 280 & 140 \\
\hline $\begin{array}{l}\text { rice } \\
\text { Cassava }\end{array}$ & $\begin{array}{l}6 \cdot 0 \\
0.6\end{array}$ & $\begin{array}{l}10 \cdot 0 \\
30 \cdot 0\end{array}$ & $\begin{array}{r}110 \\
30\end{array}$ & $\begin{array}{l}13 \cdot 1 \\
66\end{array}$ \\
\hline
\end{tabular}

Arranged in order of the buffering effect. (Figures obtained from ICMR Special Report No. 42, 1966. Ed. by C. Gopalan and S. C. Balasubramanian.)

Table 1 shows the amount of protein, calcium, phosphorus and magnesium present in the common foodstuffs that were investigated. They are arranged 
in order according to their buffering effect in vitro (see below). It will be seen that, in addition to protein, rice and wheat bran have a relatively high magnesium, and ragi a high calcium content.

\section{Experimental work}

The investigations fell into three parts.

(1) To determine the buffering effect of the food substances in vitro;

(2) to determine the gastric acid secretion in response to the food substances;

(3) to determine whether the food substances contained any pepsin inhibitors.

\section{Buffering effect in vitro}

This was investigated in three ways.

(a) Titration with $0 \cdot 1 \mathrm{~N} \mathrm{HCl}$ to $\mathrm{pH} 1 \cdot 5$. The food substances were cooked by steaming for $1 \mathrm{hr}$, dried in a hot air oven and powdered. $2 \mathrm{~g}$ were taken and soaked in $10 \mathrm{ml}$. distilled water for $12 \mathrm{hr}$. The samples were then titrated with $0.1 \mathrm{~N} \mathrm{HCl}$ to $\mathrm{pH} 1.5$ using a $\mathrm{pH}$ meter. The results expressed in $\mathrm{ml}$ of $0 \cdot 1 \mathrm{~N} \mathrm{HCl}$ are shown in Table 2.

TABLE 2. Amount of $0.1 \mathrm{~N} \mathrm{HCl}$ required to reach $\mathrm{pH} 1.5$ when added to $2 \mathrm{~g}$ of foodstuff

\begin{tabular}{lc}
\hline & Ml $0 \cdot 1 \mathrm{~N} \mathrm{HCl}$ \\
\hline Control (water $10 \mathrm{ml}$ ) & $7 \cdot 0$ \\
Rice bran & 55.0 \\
Ragi & 22.0 \\
Unmilled rice & $20 \cdot 0$ \\
Whole wheat flour & $20 \cdot 0$ \\
Cholam (Jowar) & 16.0 \\
Polished rice & 14.0 \\
White flour & $10 \cdot 0$ \\
\hline
\end{tabular}

(b) An investigation into the effect of pepsin digestion on the buffering action of the protein content of food substances. In a series of two experiments the food substances were prepared as in the first investigation. $2 \mathrm{~g}$ of each was soaked in $10 \mathrm{ml}$ of distilled water for $12 \mathrm{hr}$ and then $10 \mathrm{ml}$ of filtered human gastric juice were added. The $\mathrm{pH}$ was recorded before and after $1 \mathrm{hr}$ incubation at $37^{\circ} \mathrm{C}$ (Table 3a). In the second experiment the samples, after digestion, were also titrated with $0 \cdot 1 \mathrm{~N} \mathrm{NaOH}$ to $\mathrm{pH} 7 \cdot 4$ using phenol red as an indicator (Table $3 \mathrm{~b}$ ).

(c) $\mathrm{pH}$ titration curves to show the $\mathrm{pH}$ range over which the buffers have greatest effect. $2 \mathrm{~g}$ of the dried cooked food substances prepared as before were titrated with $1 \mathrm{ml}$ increments of $0 \cdot 1 \mathrm{~N} \mathrm{HCl}$, and $\mathrm{pH}$ titration curves were plotted (Fig. 1).
TABLE 3a. The effect of foodstuffs on the pH of gastric juice before and after $1 \mathrm{hr}$ digestion at $37^{\circ} \mathrm{C}$

\begin{tabular}{lccccc}
\hline & \multicolumn{2}{c}{$1 . \mathrm{pH}$} & & \multicolumn{2}{c}{$2 . \mathrm{pH}$} \\
\cline { 2 - 3 } \cline { 5 - 6 } & Before & After & & Before & After \\
\hline Polished rice & 2.45 & 2.67 & & 1.82 & 1.97 \\
Rice water & 2.45 & 2.30 & & 3.26 & 4.23 \\
Rice+30\% bran & & & & & \\
Rice bran & 4.18 & 5.60 & & & \\
White flour & 2.46 & 3.52 & & & \\
Wholemeal flour & 3.18 & 4.32 & & & \\
Wheat bran & 3.82 & 5.35 & & & \\
Millet & 2.85 & 3.63 & & 2.50 & 3.00 \\
Ragi & & & & 1.71 & 1.71 \\
Control & 2.37 & 2.12 & & & \\
\hline
\end{tabular}

TABLE 3b. Effect of $1 \mathrm{~g}$ of foodstuff on the titratable acidity of $10 \mathrm{ml}$ human gastric juice after digestion for $1 \mathrm{hr}$ expressed as mEq of acid neutralized

\begin{tabular}{lc}
\hline & $\begin{array}{c}\text { mEq of acid } \\
\text { neutralized }\end{array}$ \\
\hline $1 \mathrm{~g}$ rice & 0.030 \\
$1 \mathrm{~g}$ rice $+30 \%$ bran & $0 \cdot 105$ \\
$1 \mathrm{~g}$ ragi & 0.090 \\
\hline
\end{tabular}

Titration done with $0 \cdot 1 \mathrm{~N} \mathrm{NaOH}$ to $\mathrm{pH} 7 \cdot 4$ using phenol red as an indicator.

\section{Results}

Tables 2 and 3a, b and Fig. 1 all show that rice bran and some unrefined grains (ragi, maize, wholemeal wheat) buffer more acid than the refined foodstuffs (polished rice, cassava or white flour). Figure 1 shows that the buffering effect is most marked over the $\mathrm{pH}$ range of $3-1 \cdot 5$. Table 3 a shows that digestion by pepsin does increase the buffering effect of food substances, the effect being greater in those that are less refined. According to Table $3 \mathrm{~b}$ if $37.5 \mathrm{mEq}$ is taken as being the average $1 \mathrm{hr}$ maximal acid output in a duodenal ulcer patient (Kay, 1962) this amount requires the following quantities of food to buffer it to $\mathrm{pH}$ 7.4: polished rice, $1250 \mathrm{~g}$; unpolished rice, $357 \mathrm{~g}$; ragi, $417 \mathrm{~g}$. (It is estimated that a normal fullsized meal will stimulate an output equal to the maximal acid output.)

\section{Gastric acid secretion in response to food sub- stances}

This was investigated by two series of experiments. Series (i)

Fifty-one Fractional Test Meals were done on seventeen Indian patients with radiologically proven duodenal ulcer using the following food substances: $50 \mathrm{~g}$ cooked polished rice; $50 \mathrm{~g}$ cooked unmilled rice; $50 \mathrm{~g}$ cooked polished rice $+25 \%$ rice bran; 


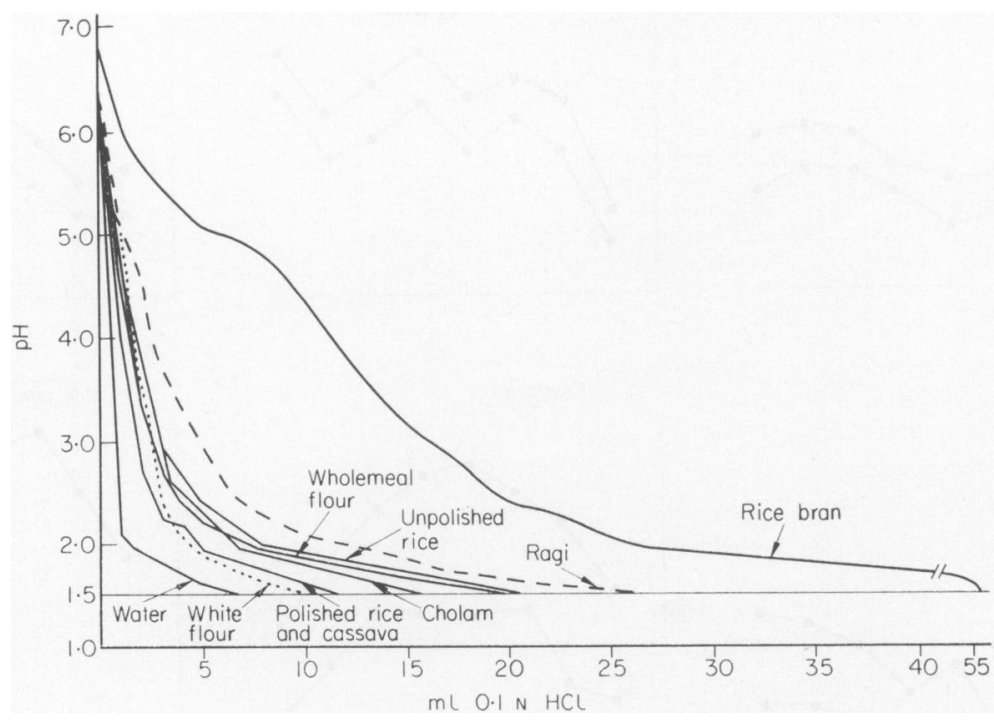

Fig. 1. Curves showing the $\mathrm{pH}$ values when $2 \mathrm{~g}$ of cooked, dried food substance is titrated with $0 \cdot 1 \mathrm{~N} \mathrm{HCl}$.

$50 \mathrm{~g}$ cooked rice bran; $50 \mathrm{~g}$ cooked ragi; $50 \mathrm{~g}$ cooked cholam (jowar); $50 \mathrm{~g}$ polished rice cooked with 120 $\mathrm{ml}$ full cream milk; $50 \mathrm{~g}$ cooked polished rice with $3.4 \mathrm{~g} \mathrm{CaCO}_{3}$ and $3.4 \mathrm{~g} \mathrm{MgCO}_{3} ; 50 \mathrm{~g}$ dried full cream milk powder.

\section{Method}

Each patient had test meals on 3 successive days using polished rice on the first day and two of the other substances on the subsequent days. At that time no $\mathrm{pH}$ meter was available in the Mission Hospital and the aspirates were titrated with $0 \cdot 1 \mathrm{~N}$ $\mathrm{NaOH}$ using Topfer's reagent as an indicator, which meant that the results were expressed using the old convention of free and total acid.

\section{Results}

Figure 2 shows the mean values of 'total' and 'free' acid in response to the different combinations. The graph of the values for polished rice for each group of patients is shown on the left. The 'total' acid concentration was higher in the presence of bran, milk and alkalies, but ragi and cholam gave similar levels to polished rice. The 'free' acid levels followed a similar pattern, except in the case of milk powder which had a more powerful and prolonged buffering effect with lower levels of 'free' acid.

\section{Series (ii)}

When a $\mathrm{pH}$ meter became available, a series of test meals was done on five normal subjects using the following combinations of food substances:

(a) four subjects: $50 \mathrm{~g}$ cooked polished rice; $50 \mathrm{~g}$ cooked polished rice $+30 \%$ rice bran; (b) one subject: $50 \mathrm{~g}$ cooked polished rice; $25 \mathrm{~g}$ cooked polished rice $+25 \mathrm{~g}$ corned beef; $25 \mathrm{~g}$ cooked polished rice $+25 \mathrm{~g}$ wheat bran; $35 \mathrm{~g}$ cooked polished rice $+15 \mathrm{~g}$ rice bran.

Samples were taken every $15 \mathrm{~min}$ for $\mathrm{pH}$ estimations.

\section{Results}

The timing of the responses in the four patients in Series (ii)(a) differed making mean values difficult to interpret, but the patterns of response were consistent and Fig. 3 is shown as an example of one of the subjects. Figure 4 shows the results in Series (ii)(b). The addition of wheat or rice bran produced a shortlived fall in acidity due to initial buffering followed by a sustained rise in acidity to higher levels than with polished rice alone. The addition of beef produced no initial buffering but a rapid fall in $\mathrm{pH}$ which was not sustained as long as with the brans.

\section{The effect of food substances on pepsin activity} in vitro

\section{Method}

$2.5 \mathrm{~g}$ of cooked, dried and powdered cereal were taken and incubated at $37^{\circ} \mathrm{C}$ for $30 \mathrm{~min}$ with $50 \mathrm{ml}$ of synthetic gastric juice $(1.5 \%$ pepsin in $0.1 \mathrm{~N} \mathrm{HCl}$. The solution was then filtered and the pepsin activity was estimated by a modification of Hunt's method (Hunt, 1948). Independent estimations were done in India and England.

\section{Results}

Table 4 shows the values obtained expressed as a percentage of the peptic activity of $50 \mathrm{ml}$ of the 

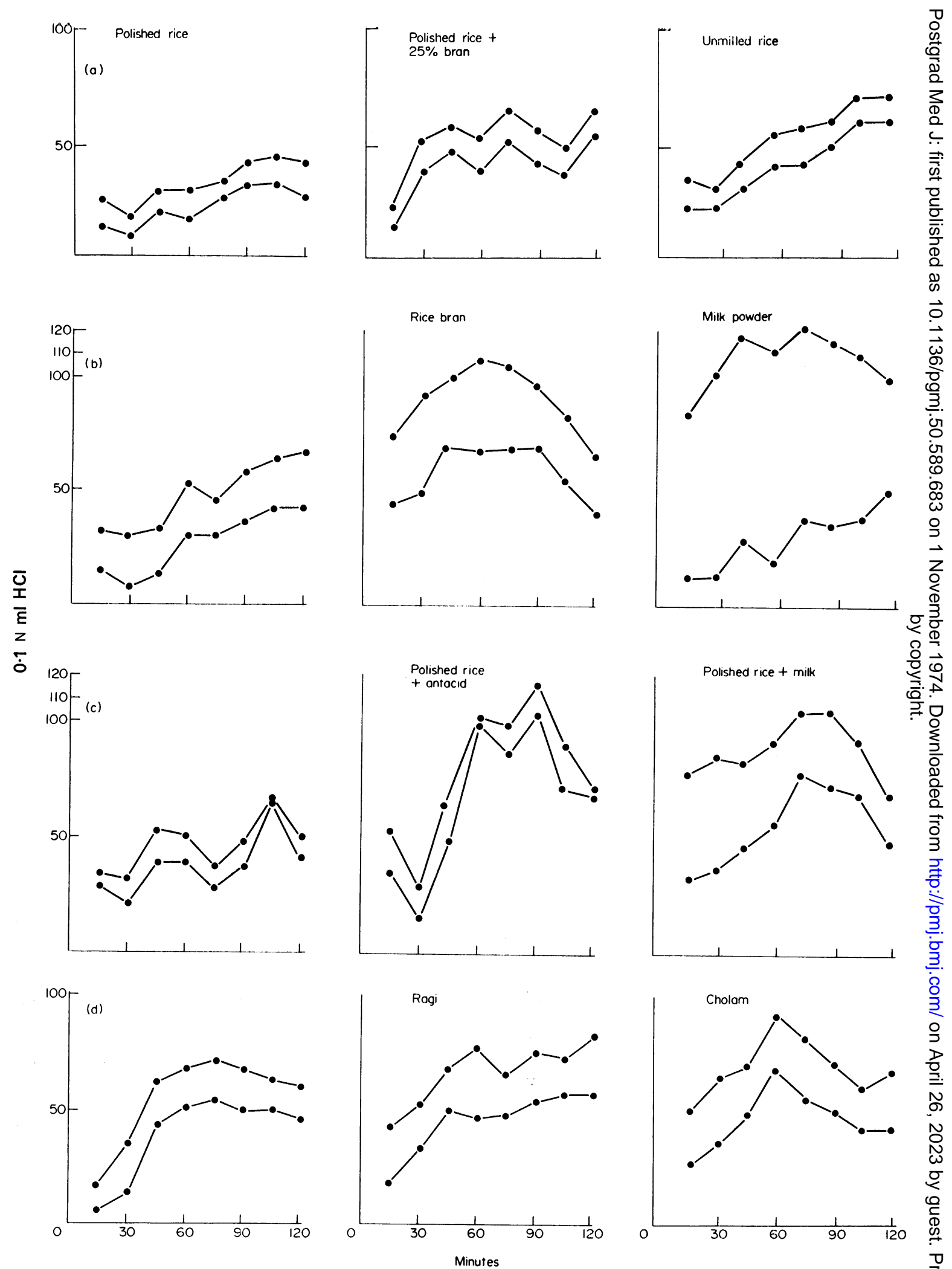

Fig. 2. Fractional test meals on duodenal ulcer patients using $50 \mathrm{~g}$ of cooked food substances. (Each patient had a test meal with polished rice followed on 2 subsequent days with test meals using other preparations.) Results of titration with $0.1 \mathrm{~N} \mathrm{NaOH}$ using Topfer's reagent as an indicator. Mean values are given: row (a) two patients; row (b) seven patients; row (c) three patients; row (d) five patients. 


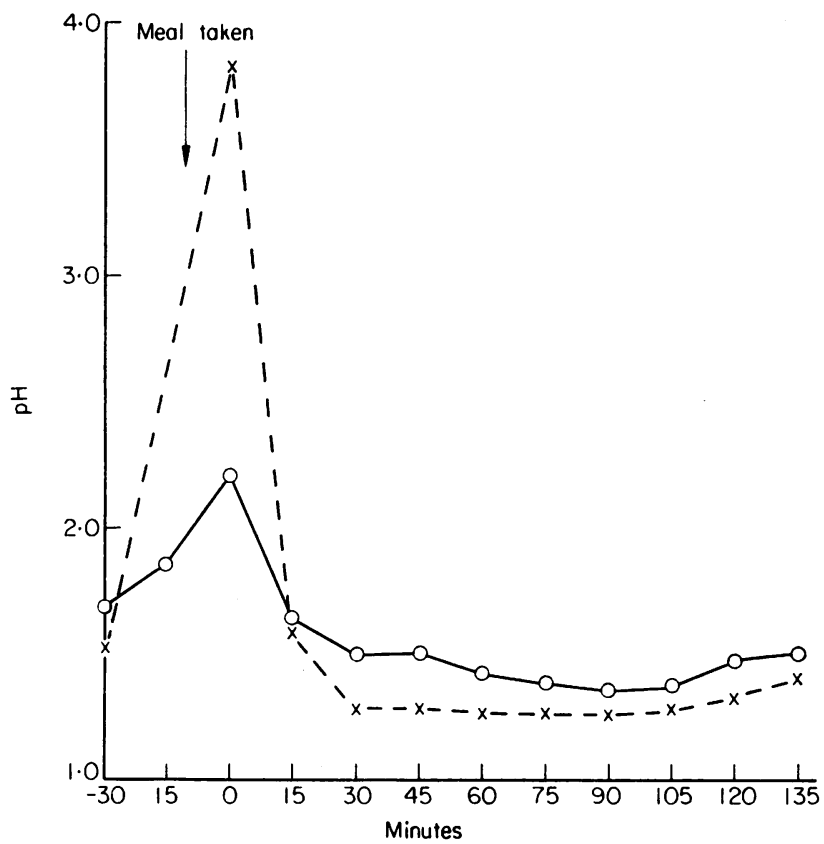

Fig. 3. The gastric responses to test meals of rice and rice plus $30 \%$ bran using pH measurements. (Example of one of the four subjects in series ii. a.) - $50 \mathrm{~g}$ rice; ------, $50 \mathrm{~g}$ rice with $30 \%$ bran.

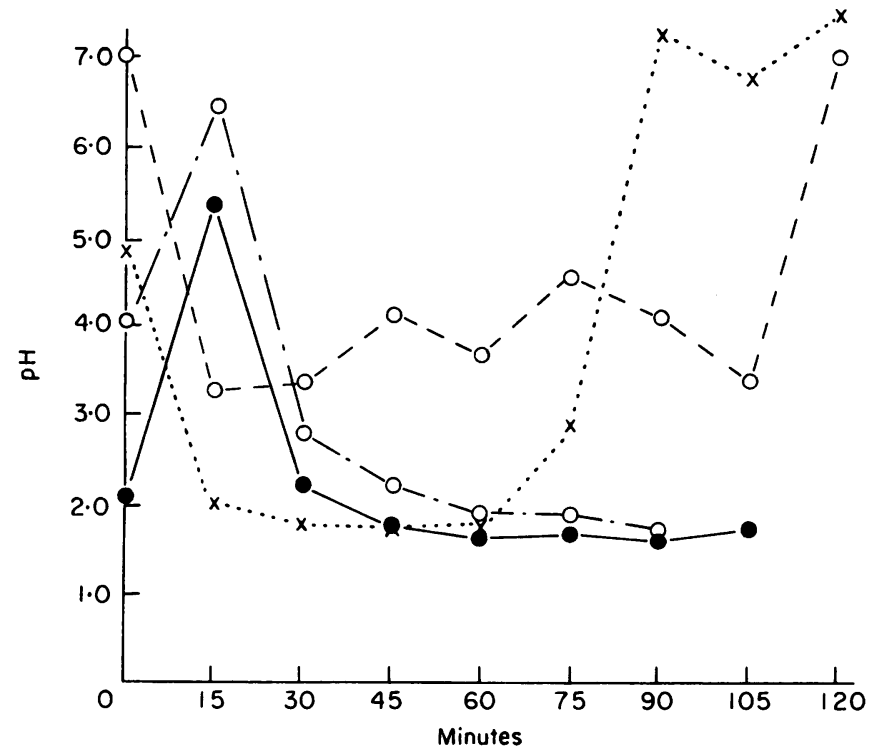

Fig. 4. The gastric responses to test meals of rice, $70 \%$ rice $+30 \%$ rice bran, $50 \%$ rice $+50 \%$ wheat bran and $50 \%$ rice $+50 \%$ corned beef. (Series ii. b.) _- - rice; - - . - rice + bran (rice); rice + bran (wheat); ........, rice + corned beef. 
synthetic gastric juice. Having regard to the variations of experimental error the results do not suggest the presence of any powerful pepsin inhibitor in rice bran or wheat bran or in any of the unrefined grains tested.

TABle 4. Pepsin activity of $50 \mathrm{ml}$ synthetic gastric juice incubated with $2 \cdot 5 \mathrm{~g}$ of foodstuff

\begin{tabular}{lcc}
\hline & 1 (U.K.) & 2 (India) \\
\hline Polished rice & $105 \%$ & $86 \%$ \\
Rice bran & $90.6 \%$ & $79 \%$ \\
White flour & $90.6 \%$ & - \\
Wholemeal wheat & - & $84 \%$ \\
Wheat bran & $102 \%$ & - \\
Maize & $\mathbf{8 8 . 8 \%}$ & - \\
Cholam (Jowar) & - & $86 \%$ \\
Ragi & - & $80 \%$ \\
Cassava & $97.4 \%$ & - \\
Cassava + millet & $97.5 \%$ & - \\
Skimmed milk powder & - & $91 \%$ \\
\hline
\end{tabular}

Results expressed as a percentage of the pepsin activity of the original solution $(1.5 \%$ pepsin in $0 \cdot 1 \mathrm{~N} \mathrm{HCl}$ ).

\section{Discussion}

The present experiments do not support Cleave's suggestion that the loss of buffer in the preparation or refinement of the staple carbohydrate food is the whole explanation of any protective effect of unrefined foods in peptic ulcer. Rice bran, wheat bran and certain unrefined grains (ragi, maize) do have a greater buffer content than do refined carbohydrate foods such as polished rice, white flour and cassava. The former, however, are also antral stimulants, resulting in an increased output of acid in the stomach. Only when the buffering effect exceeds the stimulus to greater acid output will there be a fall in acid concentration. In practice, the quantity of buffer consumed in staple diets would not often reach this level and, in the test meals reported, only occurred when pure milk powder was used. There is the possibility that inhibition of pepsin may be important, but the present experiments show that bran and unrefined grains do not inhibit pepsin activity in vitro.
It remains possible, however, that some unrefined foods may also contain a protective factor affecting mucosal resistance akin to carbenoxolone or gefarnate and, if so, this may be more important than any buffering effect. Alternatively, such a protective factor may or may not be present in the supplementary foods which are consumed with the staple carbohydrate diet. The latter possibility would provide an explanation of those rural areas on the west coast of Africa (apart from S. Nigeria), in Ethiopia, in Burundi and Rwanda, and in northern Tanzania where there is a high incidence of duodenal ulcer not apparently associated with a refined carbohydrate diet, and also such areas as those in Zaire and Tanzania where cassava is the main carbohydrate food, but duodenal ulcer is rare. This is the subject of a further investigation awaiting publication.

\section{Acknowledgments}

Thanks are expressed to the staff of the Holdsworth Memorial Hospital, Mysore, and especially to Mr K. Parker, Charge Nurse, for help with the Test Meals. The author is grateful to Mr D. Stoker and Mr Parihk of Crookes Laboratories, Basingstoke, and $\mathrm{Dr}$ Swaminathan and $\mathrm{Mr}$ Ambrose Daniells of the Central Food Technological Research Institute, Mysore, for so kindly helping with the pepsin estimations.

\section{References}

Cleave, T.L. (1962) Peptic Ulcer. John Wright \& Son: Bristol.

Cleave, T.L. (1974) The Saccharine Disease. John Wright \& Son: Bristol.

HuNT, J.N. (1948) A method for estimating peptic activity in gastric contents. Biochemical Journal, 42, 104.

KAY, A.W. (1962) Gastro-intestinal surgery and human physiology. Journal of the Royal College of Surgeons of Edinburgh, 7, 275.

LeVY, J.S. \& SILER, K.A. (1942) Clinical studies of amino acids. (The effect of oral administration of a solution of an amino acid mixture on gastric acidity.) American Journal of Digestive Diseases, 9, 354.

Tovey, F.I. (1972a) A trial of rice bran as a supplement of polished rice in the treatment of duodenal ulcer. Journal of the Christian Medical Association of India, 47, 312.

TOVEY, F.I. (1972b) Correspondence. British Medical Journal, 2, 532.

ToVEY, F.I. (1972c) Duodenal ulcer in Mysore. Tropical Geographical Medicine, 24, 107. 